\title{
Microwave-Assisted Synthesis of DUT-52 and Investigation of Its Photoluminescent Properties
}

\author{
Ruth Febriana Kesuma ${ }^{1,3}$, Aep Patah ${ }^{1,2, *}$, Yessi Permana ${ }^{1}$ \\ ${ }^{1}$ Inorganic and Physical Chemistry Research Division, Institut Teknologi Bandung, \\ Bandung, Indonesia \\ ${ }^{2}$ Research Center for Nanosciences \& Nanotechnology, Institut Teknologi Bandung, Jl. Ganesha 10, \\ Bandung, 40132, Indonesia \\ ${ }^{3}$ Department of Chemistry, Universitas Ma Chung, Villa Puncak Tidar N-01, Malang 65151, Indonesia
}

Received: 20th January 2018; Revised: 28th September 2018; Accepted: 30th September 2018; Available online: 25th January 2019; Published regularly: April 2019

\begin{abstract}
A zirconium metal-organic framework (MOF) of DUT-52 (DUT: Dresden University of Technology) was synthesized herein by reacting zirconium tetrachloride $\left(\mathrm{ZrCl}_{4}\right)$ and 2,6-naphthalenedicarboxylic acid $\left(\mathrm{H}_{2} \mathrm{NDC}\right)$ in DMF under microwave heating at $115^{\circ} \mathrm{C}$ for $25 \mathrm{~min}$. This synthetic procedure was more efficient than a solvothermal method, by which a long thermal exposure $(24 \mathrm{~h})$ of $100-150{ }^{\circ} \mathrm{C}$ was required to produce the same MOF. The MOF has a thermal stability of $560{ }^{\circ} \mathrm{C}$, prior to partial loss of interconnected 2,6-naphthalenedicarboxylate (NDC) linkers at some structure building units (SBU). Crystallinity of this DUT-52 was $c a .77 \%$, which was the same as one synthesized solvothermally. Diffuse Reflectance UV-Vis spectra revealed an absorption at $\lambda_{\text {ex }}$ of $287 \mathrm{~nm}$, which was equivalent to a bandgap energy of $4.32 \mathrm{eV}$. Electron excitations of this DUT-52 at 275 and $300 \mathrm{~nm}$ gave emission wavelength of $433 \mathrm{~nm}$ (a purple region), indicating a prospective use of DUT-52 as a photoluminescent material. Copyright (C) 2018 BCREC Group. All rights reserved
\end{abstract}

Keywords: MOF; DUT-52; Microwave Heating; Bandgap Energy; Photoluminescence

How to Cite: Kesuma, R.F., Patah, A., Permana, Y. (2019). Microwave-Assisted Synthesis of DUT-52 and Investigation of Its Photoluminescent Properties. Bulletin of Chemical Reaction Engineering \& Catalysis, 14 (1): 124-129 (doi:10.9767/bcrec.14.1.2369.124-129)

Permalink/DOI: https://doi.org/10.9767/bcrec.14.1.2369.124-129

\section{Introduction}

Physical properties of MOFs, such as surface areas, pore sizes and topologies, may be affected by types of metal clusters, organic linkers and syntheses methods [1]. An appropriate synthesis method may result in MOFs with solid structures, high crystallinity, and high thermal stability. MOFs have been widely used in het-

\footnotetext{
* Corresponding Author.

E-mail: aep@chem.itb.ac.id (A. Patah); yessi@chem.itb.ac.id (Y. Permana)

Telp: +62-22-2502103, Fax: +62-22-2502103
}

erogeneous catalyses [2-5], drug deliveries [6,7], gas storages [8,9], photocatalysis [10-12], gas sensors [13,14], and separations [15]. An improvement in synthetic procedures is of highly importance in producing MOFs with high energy efficiency. Microwave-assisted syntheses of MOFs recently are used because polar rotations of organic linkers and solvents may heat reaction systems evenly and rapidly [16]. A microwave heating may also result in homogeneous nucleations and thus, reduces crystallization time compared to a solvothermal method [17].

MOF with SBUs of oxohydroxozirconium(IV), $\left[\mathrm{Zr}_{6} \mathrm{O}_{4}(\mathrm{OH})_{4}\right]^{12+}$, and linkers of NDC was first 
synthesized by Zhong and co-workers [18] using a solvothermal method in DMF in the presence of $\mathrm{HCl}$. The group studied the MOF for sensing small molecules [18]. Kaskel and coworkers synthesized the same MOF and other $\mathrm{Zr}$ (or Hf)-NDC MOFs solvothermally in the same year, with a slight modification, i.e. employment of acetic acid with different concentrations as a structural modulator and named them DUT-52 (Zr), DUT-53 (Hf) and DUT-84 (Zr) [19]. The synthesis was conducted by heating reaction mixtures in an oven at $120{ }^{\circ} \mathrm{C}$ for $24 \mathrm{~h}$ (72 $\mathrm{h}$ for DUT-53) [18,19]. An SBU in DUT-52 is connected to 12 NDC ligands, which is isoreticular to UiO-66 [19,20], a Zr MOF with 1,4-benzenedicarboxylate (BDC) linkers. The reported DUT-52 was thermally stable up to $500{ }^{\circ} \mathrm{C}$, with BET surface area (S ВET$_{\text {BET }}$ of 1399 $\mathrm{m}^{2}$.g-1 $^{-1}$ [19]. This $S_{\text {BET was }}$ greater than that of UiO-66 [21]. A direct interaction of microwave radiation and polar reactants is possible to occur in a microwave-assisted synthesis. Thus, it offers high heating rates and possible homogeneous heating throughout the sample to feasibly complete the reaction in a very short time [1]. An example of a microwave-assisted MOF synthesis was the synthesis of MOF-5 (Zn). The MOF was synthesized using microwave irradiation for 10 to 60 min with a power up to $1 \mathrm{~kW}$ at $105{ }^{\circ} \mathrm{C}[16,17,22]$. Another example was Co-MOF-74, which was synthesized under microwave heating at $130{ }^{\circ} \mathrm{C}$ and the power of 300 $\mathrm{W}$ for $1 \mathrm{~h}$ [9]. The use of microwave heating in Zr-MOF synthesis was recently reported by Reinsch group. They reported the use of 2,5-furandicarboxylate (FDC) as linkers to generate Zr-CAU-28 (CAU: Christian-AlbrechtsUniversity), at which the SBU was connected to 8 FDC linkers [26]. We reported herein the first example of a microwave-assisted synthesis of DUT-52 in a relatively short time $(25 \mathrm{~min})$ and described its photoluminescent properties. Photoluminescent properties of MOFs may have applications in biomedical imaging, displays, electroluminescent devices, fluorescent sensors, nonlinear optics, and photocatalyses [14]. An example of MOF employment in photocatalysis was MOF-5, as reported by Llabrès et al. The MOF was used in phenol degradation using UV irradiation [11]. This MOF-5 was synthesized solvothermally from zinc salt and terephthalic acid as linkers. A photocatalyst material from $\mathrm{Zr}$ MOF of UiO-66 was reported by Shen et al. [23]. The MOF was used in $\mathrm{Cr}(\mathrm{VI})$ reduction under simulated sunlight with a reduction activity up to $35 \%$ after 3 hourirradiation. UiO-66 has an absorption band in a UV region $(320 \mathrm{~nm})$ which was correlated to a bandgap energy of $3.9 \mathrm{eV}$ [23]. Other NDC MOFs, such as DUT-53 and DUT-84 [19] were also synthesized with a long heating solvothermally. Therefore, an investigation of a more efficient synthesis method of DUT-52 and the study of its photoluminescent properties are important to evaluate the MOF as future photoluminescent materials.

\section{Materials and Methods}

\subsection{Synthesis and Activation}

All reagents, i.e. $\mathrm{H}_{2} \mathrm{NDC}$ (Sigma Aldrich, 99 \%), chloroform (Merck), HCl (Merck, $37 \%$ ), $N, N$-dimethylformamide (Merck, $99.8 \%$ ), and $\mathrm{ZrCl}_{4}$ (Merck, $99 \%$ ), were of analytical grade and used without further purification. The synthesis of DUT-52 was performed by dissolving $\mathrm{ZrCl}_{4}(175 \mathrm{mg}, 0.75 \mathrm{mmol})$ and $\mathrm{H}_{2} \mathrm{NDC} ; 162$ $\mathrm{mg}, 0.75 \mathrm{mmol})$ in DMF $(20 \mathrm{~mL})$ at room temperature $\left(28^{\circ} \mathrm{C}\right)$. Hydrochloric acid of $0.5 \mathrm{~mL}$ $(12 \mathrm{M})$ was added to the mixture to initiate the grow of crystal nucleus [18] and the mixture was sonicated for $60 \mathrm{~min}$. The mixture was capped tightly and kept in a microwave (SINEO Microwave Synthesis Workstation MAS-II). The synthesis was carried out at 110 ${ }^{\circ} \mathrm{C}$, power of $800 \mathrm{~W}$ for $25 \mathrm{~min}$. The crude product was cooled to room temperature and kept for $10 \mathrm{~min}$ to give white precipitates. The white product was filtered off, and rinsed within 3 days with DMF (once) and chloroform (twice). The product was finally dried under vacuum at $120{ }^{\circ} \mathrm{C}$ for $8 \mathrm{~h}$.

\subsection{Characterization}

Powder XRD analysis was carried out using D8 Advance Bruker diffractometer with $\mathrm{Cu}-\mathrm{K} a$ radiation $(\lambda=0.15406 \mathrm{~nm})$. FTIR analysis was carried out using a Bruker Alpha instrument (ZnSe beamsplitter) by dispersing the sample into a potassium bromide pellet. The spectrum was collected from 16 scans with a spectrum resolution of $2 \mathrm{~cm}^{-1}$. A thermogravimetric analyzer was used to get information of thermal stability of the material using NETZSCH TGA Thermoanalyzer STA 449 F3 Jupiter. Heating rate of the TGA was $40^{\circ} \mathrm{C} / \mathrm{min}$, started at room temperature $\left(28^{\circ} \mathrm{C}\right)$ and increased up to $900{ }^{\circ} \mathrm{C}$ under argon atmosphere. Percentage of reflectance $(\% \mathrm{R})$ was taken using a diffuse reflectance spectrophotometer (DRS) of Thermo Scientific Evolution 220. Value of $n$ equals 1/2 was selected in this measurement, because the nature of this sample transition was a direct allowed transition. The obtained diffuse reflectance spectra were converted to a Kubelka- 
Munk function. A vertical axis was converted to $\mathrm{F}(R \infty)$ value, which was proportional to an absorption coefficient. The $a$ in a Tauc equation [24] was substituted with $\mathrm{F}(R \infty)$. The value of $(h v F(R \infty))^{2}$ was plotted against $h v$ (described in $\mathrm{eV})$ according to a Kubelka-Munk equation [24]. A tangent line was drawn to a point of inflection of the curve and the $h v$. The bandgap energy $\left(E_{\mathrm{g}}\right)$ value was derived from a point of intersection between the tangent line and the horizontal line of $h v$. Barium sulfate was used as a reflectance coating in our DRS measurement. Photoluminescent (PL) properties of DUT-52 were measured in a solid phase at room temperature using F-7000 fluorescence spectrometer, with a xenon lamp as an excitation source.

\section{Results and Discussion}

\subsection{Microwave Assisted-synthesis of DUT-52}

We reported herein a facile and fast synthesis of DUT-52 using a microwave method. The reaction was completed in $25 \mathrm{~min}$, significantly shorter than the one with a solvothermal method $(24 \mathrm{~h})[18,19]$. PXRD patterns of the synthesized DUT-52 (Figure 1) revealed characteristic diffraction patterns of DUT-52 [18,19] at $2 \theta$ of $6.47^{\circ}$, corresponding to a $d_{111}$ reflection and at $7.45^{\circ}$, corresponding to a $d_{200}$ reflection [19]. Coordinated NDC ligands to $\mathrm{Zr}$ in $\left[\mathrm{Zr}_{6} \mathrm{O}_{4}(\mathrm{OH})_{4}\right]^{12+}$ clusters were observed by a slight shift of carbonyl groups at NDC from $1687 \mathrm{~cm}^{-1}$ in a free $\mathrm{H}_{2} \mathrm{NDC}$ ligand to $1651 \mathrm{~cm}^{-1}$ in the MOF (Figure 2), describing a weakened carbonyl vibration after metalation.

Average crystallites size of this DUT-52 was $42 \mathrm{~nm}$, which was smaller than that of UiO-66 (150-200 nm) [21]. In contrast to a long crystal

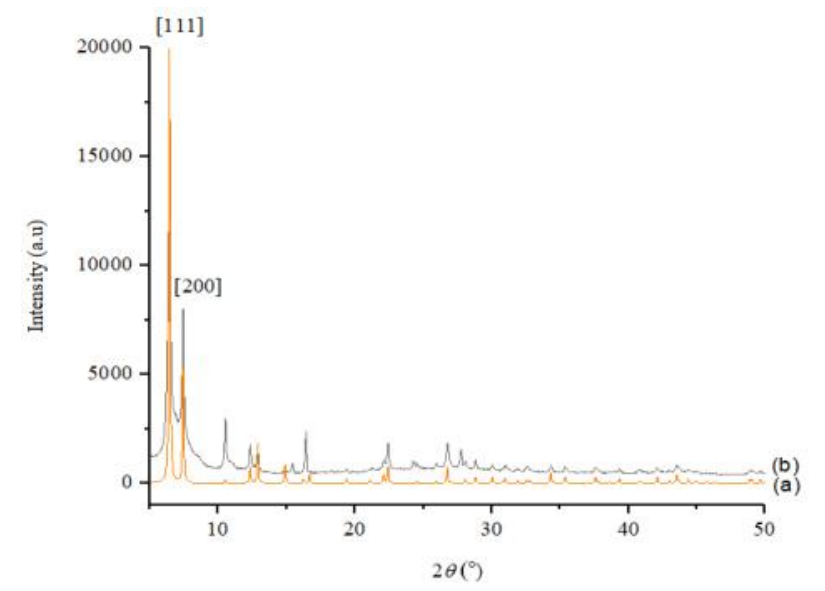

Figure 1. PXRD patterns of DUT-52 reference (a) [18] and DUT-52 (as synthesized) (b) growing of a solvothermal method, the short heating by microwave was able to generate a relatively good crystal quality of DUT-52. In fact, the crystallinity of this MOF was relatively the same as a solvothermally prepared DUT-52 (70 \%) [27].

Thermogravimetric analysis of assynthesized DUT-52 showed three weight-loss steps between 25 and $600{ }^{\circ} \mathrm{C}$ (Figure 3). The first weight-loss ( 25 to $120^{\circ} \mathrm{C}$ ) of $13 \%$ was attributed to the water removal. The second loss $\left(150\right.$ to $400{ }^{\circ} \mathrm{C}$ ) of $16.5 \%$ was the removal of solvents (DMF). The framework started decomposing $(22.5 \%)$ in third weight-loss at $560{ }^{\circ} \mathrm{C}$, attributed to the loss of NDC partially. This is likely the maximum thermal stability of DUT52 before partial loss of the linker. DUT-52 was reported to have 12 interconnected-NDC at its SBU [19]. Partial loss of NDC might give a reduced number of interconnected-NDC at some SBUs. Kaskel has reported a reduction of SBU connectivity from 12-NDC (DUT-52) to 8-NDC (DUT-53) and to 6-NDC (DUT-84) by increasing concentrations of acetic acid in the reaction [19]. Here, the MOF thermally unchanged from $600{ }^{\circ} \mathrm{C}$ up to our final TGA observation of 900 ${ }^{\circ} \mathrm{C}$ (Figure 3). Zhong [18] and Kaskel [19] reported a slightly lower thermal stability of their solvothermally synthesized DUT-52, indicated by the earlier framework decomposition at $c a .500{ }^{\circ} \mathrm{C}$ and significantly continued afterwards. Thus, we observed a relatively higher thermal stability of DUT-52 which was prepared by a microwave heating, compared to the one prepared solvothermally.

\subsection{Luminescence Character}

Optical absorption of this DUT-52 was described in diffuse reflectance UV-Vis spectra

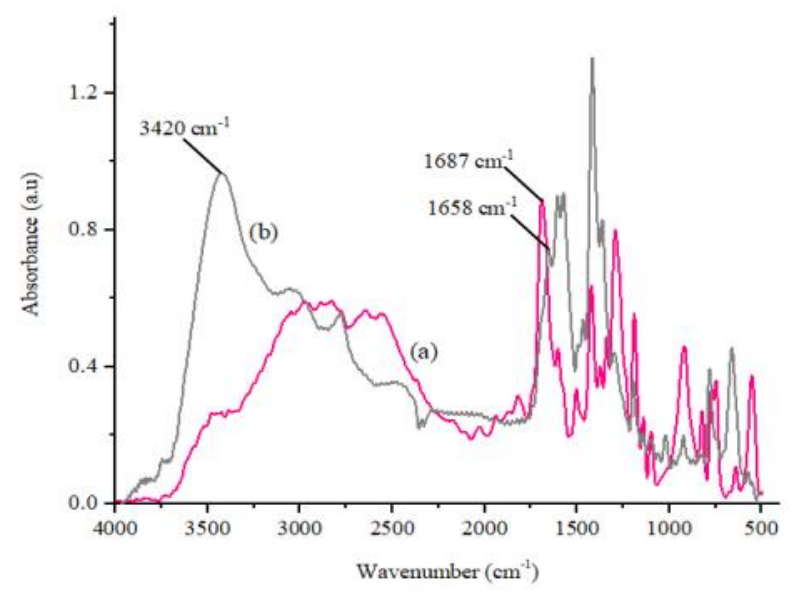

Figure 2. FTIR spectra of (a) $\mathrm{H}_{2} \mathrm{NDC}$ and (b) DUT-52 (as-synthesized) 
(Figure 4). The percentage of reflectance (\%R) was used to calculate the bandgap energy of the MOF using a Kubelka-Munk equation and Tauc Plot [24]. The bandgap energy $\left(E_{\mathrm{g}}\right)$ of assynthesized DUT-52 was $4.32 \mathrm{eV}$, which might be classified as a semiconductor material [25]. The presence of aromatics groups in DUT-52 linkers might affect optical properties of the material. The main absorption band of DUT-52 was at $287 \mathrm{~nm}$. This likely described an electron transition from the linker to $\mathrm{Zr}(\mathrm{IV})$. The MOF thus might demonstrate a photoluminescence under a light exposure with a wavelength higher than $287 \mathrm{~nm}$.

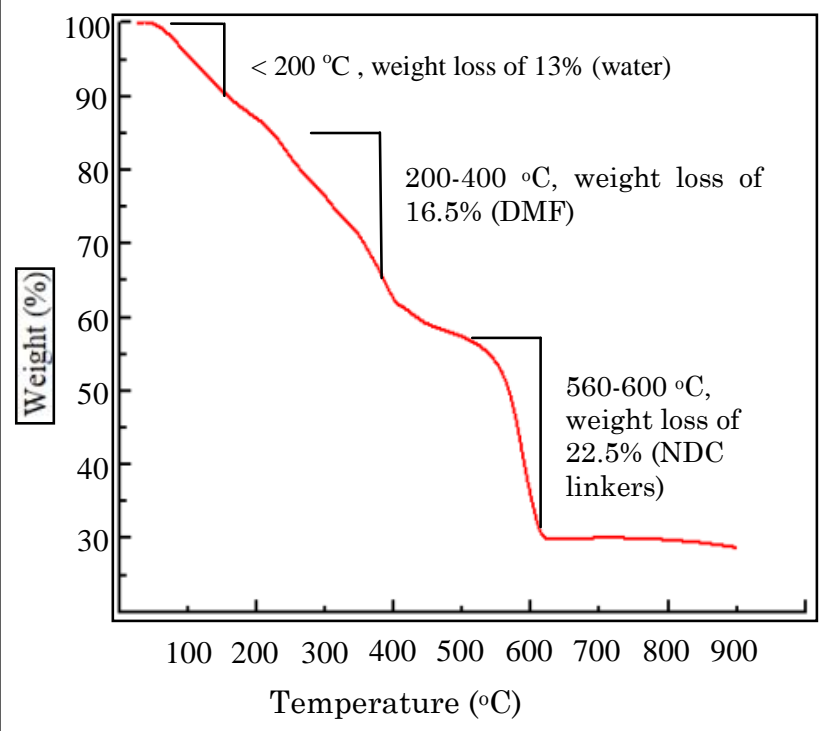

Figure 3. TGA thermogram of DUT-52 (assynthesized)

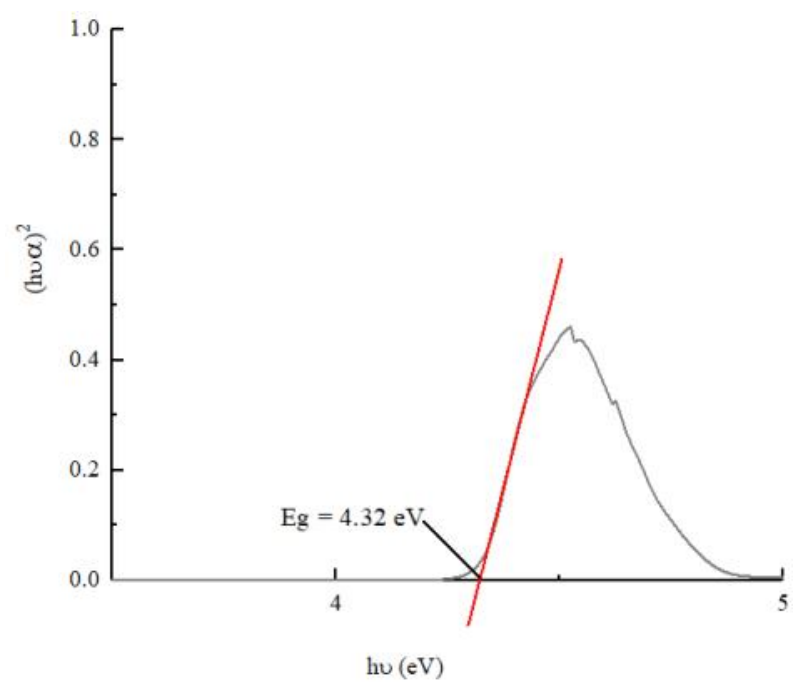

Figure 4. Band gap energy of DUT-52 (assynthesized)
To observe the luminescence behavior, this DUT-52 was analyzed by a solid-state photoluminescence (PL) spectroscopy. PL analysis described an emission wavelength of this MOF at $433 \mathrm{~nm}$ in response to its electrons excitations at 275 and $300 \mathrm{~nm}$ (Figure 5). Zhong reported that a free NDC ligand gave a lower emission wavelength (356 nm) [18], indicating a redshift behavior of DUT-52 crystals to a visible region. The emission intensity was reported to be 5 times higher in the MOF [18], and thus confirmed the benefit of a MOF structure in the luminescence. It was also observed that higher energy given for an excitation ( $\lambda_{e x}$ of $275 \mathrm{~nm}$ ) resulted in higher intensity of the resulted emmision (Figure 5). This might describe a way to tune brightness of the luminescence. The luminescence itself could be rationalized by a strong electronic coupling between NDC linkers through $\left[\mathrm{Zr}_{6} \mathrm{O}_{4}(\mathrm{OH})_{4}\right]^{12+}$ cluster and $\Pi-\Pi^{*}$ transitions of the linker [18].

\section{Conclusions}

A good crystalline DUT-52 with MOF crystallinity up to $77 \%$ was successfully synthesized by a microwave heating in only $25 \mathrm{~min}$. The MOF has a relatively higher thermal stability compared to the one prepared solvothermally. Diffuse reflectance UV-Vis spectra revealed an absorption at $\lambda_{\text {ex }} 287 \mathrm{~nm}$ which were identical to a bandgap energy of $4.32 \mathrm{eV}$. Electrons excitations at 275 and $300 \mathrm{~nm}$ gave an emission at $433 \mathrm{~nm}$ and thus indicated a possible application of this MOF to work as a photoluminescence material in a visible region.

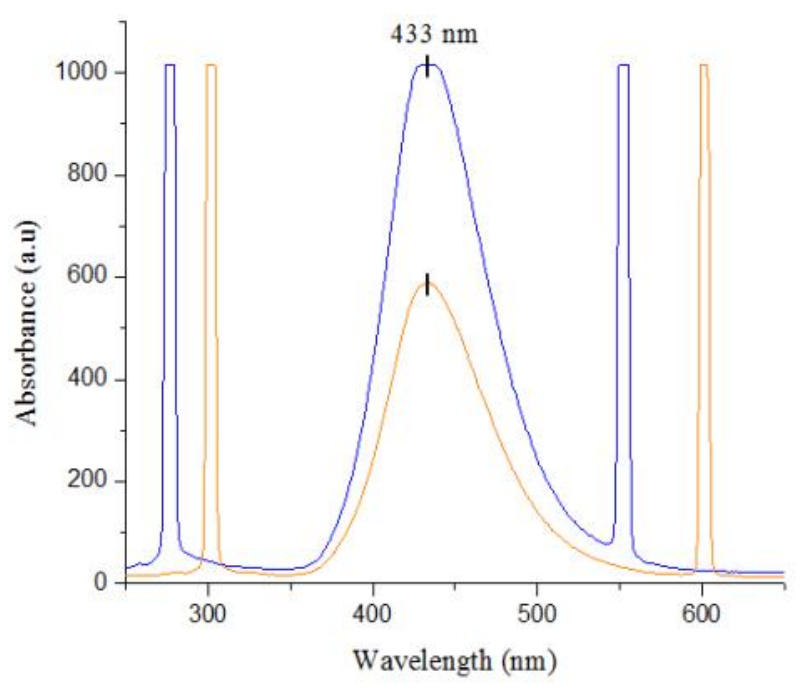

Figure 5. Photoluminescence spectra of DUT52 (as-synthesized) at $\lambda_{e x}$ of $275 \mathrm{~nm}$ (blue) and $300 \mathrm{~nm}$ (orange) 


\section{Acknowledgments}

Authors acknowledge Hibah PUPT-DIKTI FY 2015-2016 for financial supports on ZrMOFs research. Authors are grateful to Dr. Veinardi Suendo and Dr. Bambang Prijamboedi for the given permission to use DRS UVVis and PL spectroscopies. We also acknowledge Ms. Sri Rahayu for assistances in handling SINEO Microwave Workstation MAS-II. RFK thanks BPP-DN DIKTI (2014-2016) for a graduate program scholarship at Chemistry Department of Institut Teknologi Bandung (ITB). AP acknowledges World Class Professors Program of ITB (2017-2018) for supporting the research on MOFs.

\section{References}

[1] Stock, N., Biswas, S. eds. (2012). Synthesis of Metal-Organic Frameworks (MOFs): Routes to Various MOF Topologies, Morphologies, and Composites. Chemical Reviews, 112: 933969.

[2] Nguyen, L.T.L., Nguyen, C.V., Dang, G.H., Le, K.K.A., Phan, N.T.S. (2011). Towards Applications of Metal-Organic Frameworks in Catalysis: Friedel - Crafts Acylation Reaction over IRMOF-8 as an Efficient Heterogeneous Catalyst. Journal of Molecular Catalysis A: Chemical, 349: 28-35.

[3] Calleja, G., Sanz, R., Orcajo, G., Briones, D., Leo, P., Martínez, F. (2014). Copper-Based MOF-74 Material as Effective Acid Catalyst in Friedel - Crafts Acylation of Anisole. Catalysis Today, 227: 130-137.

[4] Nguyen, L.T.L., Nguyen, T.T., Nguyen, K.D., Phan, N.T.S. (2012). Metal-Organic Framework MOF-199 as an Efficient Heterogeneous Catalyst for the Aza-Michael Reaction. Applied Catalysis A: General, 425-426: 44-52.

[5] Phan, N.T.S., Nguyen, T.T., Nguyen, C.V., Nguyen, T.T. (2013). Ullmann-Type Coupling Reaction using Metal-Organic Framework MOF-199 as an Efficient Recyclable Solid Catalyst. Applied Catalysis A: General, 457: 69-77.

[6] Horcajada, P., Chalati, T., Serre, C., Gillet, B., Sebrie, C., Baati, T. (2009). Porous MetalOrganic-Framework Nanoscale Carriers as a Potential Platform for Drug Delivery and Imaging. Nature Materials, 9: 172-178.

[7] Taylor-Pashow, K.M.L., Della Rocca, J., Xie, Z., Tran, S., Lin, W. (2009). Postsynthetic Modifications of Iron-Carboxylate Nanoscale Metal-Organic Frameworks for Imaging and Drug Delivery. Journal of the American Chemical Society, 131: 14261-14263.
[8] Fang, Q., Zhu, G., Jin, Z., Ji, Y., Ye, J., Xue, M. (2007). Mesoporous Metal Organic Framework with Rare ETB Topology for Hydrogen Storage and Dye Assembly. Angewandte Chemie International Edition, 46: 6638-6642.

[9] Cho, H., Yang, D., Kim, J., Jeong, S., Ahn, W. (2012). $\mathrm{CO}_{2}$ Adsorption and Catalytic Application of Co-MOF-74 Synthesized by Microwave Heating. Catalysis Today, 185(1): 3540.

[10] Nasalevich, M.A., Goesten, M.G., Savenije, T.J., Kapteijn, F., Gascon, J. (2013). Enhancing Optical Absorption of Metal-Organic Frameworks for Improved Visible Light Photocatalysis. Chemical Communications, 49: 10575-10577.

[11] Llabres, F.X., Corma, A., Garcia, H. (2007). Applications for Metal Organic Frameworks (MOFs) as Quantum Dot Semiconductors. The Journal of Physical Chemistry C, 111: 80-85.

[12] Pu, S., Xu, L., Sun, L., Du, H. (2015). Tuning the Optical Properties of the Zirconium UiO-66 Metal-Organic Framework for Photocatalytic Degradation of Methyl Orange. Inorganic Chemistry Communications, 52: 50-52.

[13] Guo, Z., Xu, H., Su, S., Cai, J., Dang, S., Xiang, S. (2011). A Robust Near Infrared Luminescent Ytterbium Metal-Organic Framework for Sensing of Small Molecules. Chemical Communications, 47: 5551-5553.

[14] Cui, Y., Yue, Y., Qian, G., Chen, B. (2012). Luminescent Functional Metal-Organic Frameworks. Chemical Reviews, 112: 11261162.

[15] Corno, M., Rimola, A., Bolis, V., Ugliengo, P. (2010). Hydroxyapatite as a Key Biomaterial: Quantum-Mechanical Simulation of Its Surfaces in Interaction with Biomolecules. Physical Chemistry Chemical Physics, 12: 63096329.

[16] Lu, C., Liu, J., Xiao, K., Harris, A.T. (2010). Microwave Enhanced Synthesis of MOF-5 and Its $\mathrm{CO}_{2}$ Capture Ability at Moderate Temperatures Across Multiple Capture and Release Cycles. Chemical Engineering Journal, 156: 465-470.

[17] Choi, J., Son, W., Kim, J., Ahn, W. (2008). Metal-Organic Framework MOF-5 Prepared by Microwave Heating: Factors to be Considered. Microporous Mesoporous Materials, 116: 727-731.

[18] Zhang, W., Huang, H., Liu, D., Yang, Q., Xiao, Y., Ma, Q., Zhong, C (2013). A New Metal - Organic Framework with High Stability Based on Zirconium for Sensing Small Molecules. Microporous Mesoporous Materials, 171: 118-124. 
[19] Bon, V., Senkovska, I., Weiss, M.S., Kaskel, S. (2013). Tailoring of Network Dimensionality and Porosity Adjustment in Zr- and Hf-Based MOFs. Crystal Engineering Communications, 15: 9572-9577.

[20] Arrozi, U.S.F., Wijaya, H.W., Patah, A., Permana, Y. (2015). Efficient Acetalization of Benzaldehydes using UiO-66 and UiO-67: Substrates Accessibility or Lewis Acidity of Zirconium. Applied Catalysis A: General, 506: 77-84.

[21] Zhao, Q., Yuan, W., Liang, J., Li, J. (2013). Synthesis and Hydrogen Storage Studies of Metal-Organic Framework UiO-66. International Journal of Hydrogen Energy, 38: 13104-13109.

[22] Yoo, Y., Lai, Z., Jeong, H. (2009). Fabrication of MOF-5 Membranes using MicrowaveInduced Rapid Seeding and Solvothermal Secondary Growth. Microporous Mesoporous Materials, 123: 100-106.
[23] Shen, L., Liang, R., Luo, M., Jing, F., Wu, L. (2015). Electronic Effects of Ligand Substitution on Metal Organic Frameworks Photocatalysts: The Case Study of UiO-66. Physical Chemistry Chemical Physics, 17: 117-121.

[24] Murphy, A.B. (2007). Band-Gap Determination from Diffuse Reflectance Measurements of Semiconductor Films, and Application to Photoelectrochemical. Solar Energy Materials \& Solar Cells, 91: 1326-1337.

[25] Linsebigler, A.L., Lu, G., Yates, J.T. (1995). Photocatalysis on $\mathrm{TiO}_{2}$ Surfaces: Principles, Mechanisms, and Selected Results. Chemical Reviews, 95(3): 735-758.

[26] Dreischarf, A.C., Lammert, M., Stock, N., Reinsch H. (2017). Green Synthesis of Zr-CAU28: Structure and Properties of the First $\mathrm{Zr}$ MOF Based on 2,5-Furandicarboxylic Acid. Inorganic Chemistry, 56: 2270-2277.

[27] Reproduction of Solvothermally PreparedDUT-52 was Done According to Reference [18] and Taken as a Benchmark for the Crystallinity of DUT-52. 